\title{
Pre-operative fluid resuscitation in the emergency general surgery septic patient: does it really matter?
}

\author{
Benjamin Moran \\ Einstein Healthcare Network, Sidney Kimmel Medical College at Thomas Jefferson University, Einstein \\ Medical Center, Klein Building, Suite 101, 5401 Old York Road, Philadelphia, PA, 19141, USA \\ Erin Major \\ R Adams Cowley Shock Trauma Center, University of Maryland School of Medicine, Baltimore, MD, USA \\ Joseph A Kufera \\ R Adams Cowley Shock Trauma Center, University of Maryland School of Medicine, Baltimore, MD, USA \\ Samuel A Tisherman \\ R Adams Cowley Shock Trauma Center, University of Maryland School of Medicine, Baltimore, MD, USA \\ Jose Diaz

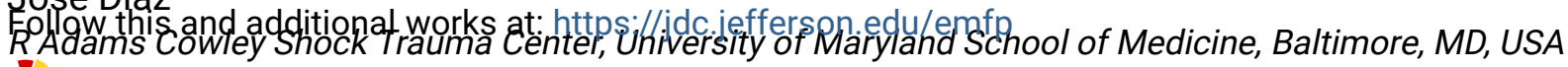 \\ Part of the Emergency Medicine Commons \\ Let us know how access to this document benefits you
}

\section{Recommended Citation}

Moran, Benjamin; Major, Erin; Kufera, Joseph A; Tisherman, Samuel A; and Diaz, Jose, "Preoperative fluid resuscitation in the emergency general surgery septic patient: does it really matter?" (2021). Department of Emergency Medicine Faculty Papers. Paper 159.

https://jdc.jefferson.edu/emfp/159

This Article is brought to you for free and open access by the Jefferson Digital Commons. The Jefferson Digital Commons is a service of Thomas Jefferson University's Center for Teaching and Learning (CTL). The Commons is a showcase for Jefferson books and journals, peer-reviewed scholarly publications, unique historical collections from the University archives, and teaching tools. The Jefferson Digital Commons allows researchers and interested readers anywhere in the world to learn about and keep up to date with Jefferson scholarship. This article has been accepted for inclusion in Department of Emergency Medicine Faculty Papers by an authorized administrator of the Jefferson Digital Commons. For more information, please contact: JeffersonDigitalCommons@jefferson.edu. 


\title{
Pre-operative fluid resuscitation in the emergency general surgery septic patient: does it really matter?
}

\author{
Benjamin Moran ${ }^{1 *}$, Erin Major², Joseph A. Kufera², Samuel A. Tisherman² and Jose Diaz²
}

\begin{abstract}
Objective: Emergency general surgery (EGS) patients presenting with sepsis remain a challenge. The Surviving Sepsis Campaign recommends a $30 \mathrm{~mL} / \mathrm{kg}$ fluid bolus in these patients, but recent studies suggest an association between large volume crystalloid resuscitation and increased mortality. The optimal amount of pre-operative fluid resuscitation prior to source control in patients with intra-abdominal sepsis is unknown. This study aims to determine if increasing volume of resuscitation prior to surgical source control is associated with worsening outcomes.
\end{abstract}

Methods: We conducted an 8-year retrospective chart review of EGS patients undergoing surgery for abdominal sepsis within $24 \mathrm{~h}$ of admission. Patients in hemorrhagic shock and those with outside hospital index surgeries were excluded. We grouped patients by increasing pre-operative resuscitation volume in $10 \mathrm{ml} / \mathrm{kg}$ intervals up to $>70$ $\mathrm{ml} / \mathrm{kg}$ and later grouped them into $<30 \mathrm{ml} / \mathrm{kg}$ or $\geq 30 \mathrm{ml} / \mathrm{kg}$. A relative risk regression model compared amounts of fluid administration. Mortality was the primary outcome measure. Secondary outcomes were time to operation, ventilator days, and length of stay (LOS). Groups were compared by quick Sequential Organ Failure Assessment (qSOFA) and SOFA scoring systems.

Results: Of the 301 patients included, the mean age was 55, 51\% were male, 257 (85\%) survived to discharge. With increasing fluid per $\mathrm{kg}(<10$ to $<70 \mathrm{ml} / \mathrm{kg})$, there was an increasing mortality per decile, $8.8 \%$ versus $31.6 \%(p=$ 0.004). Patients who received $<30 \mathrm{~mL} / \mathrm{kg}$ had lower mortality $(11.3 \mathrm{vs} 21 \%)$ than those who received $>30 \mathrm{ml} / \mathrm{kg}$ $(p=0.02)$. These groups had median qSOFA scores (1.0 vs. 1.0, $p=0.06)$. There were no differences in time to operation (6.1 vs $4.9 \mathrm{~h} p=0.11$ ), ventilator days ( 1 vs $3, p=0.08$ ), or hospital LOS ( 8 vs 9 days, $p=0.57$ ). Relative risk regression correcting for age and physiologic factors showed no significant differences in mortality between the fluid groups.

Conclusions: Greater pre-operative resuscitation volumes were initially associated with significantly higher mortality, despite similar organ failure scores. However, fluid volumes were not associated with mortality following adjustment for other physiologic factors in a regression model. The amount of pre-operative volume resuscitation was not associated with differences in time to operation, ventilator days, ICU or hospital LOS.

Keywords: Emergency general surgery, Abdominal Sepsis, Fluid resuscitation, Source control, Pre-operative resuscitation

\footnotetext{
* Correspondence: moranben@einstein.edu

Presentations: Society of Critical Care Medicine, February 2020

'Einstein Healthcare Network, Sidney Kimmel Medical College at Thomas

Jefferson University, Einstein Medical Center, Klein Building, Suite 101, 5401

Old York Road, Philadelphia, PA 19141, USA

Full list of author information is available at the end of the article
}

\section{$\triangle B M C$}

(c) The Author(s). 2021 Open Access This article is licensed under a Creative Commons Attribution 4.0 International License, which permits use, sharing, adaptation, distribution and reproduction in any medium or format, as long as you give appropriate credit to the original author(s) and the source, provide a link to the Creative Commons licence, and indicate if changes were made. The images or other third party material in this article are included in the article's Creative Commons licence, unless indicated otherwise in a credit line to the material. If material is not included in the article's Creative Commons licence and your intended use is not permitted by statutory regulation or exceeds the permitted use, you will need to obtain permission directly from the copyright holder. To view a copy of this licence, visit http://creativecommons.org/licenses/by/4.0/ The Creative Commons Public Domain Dedication waiver (http://creativecommons.org/publicdomain/zero/1.0/) applies to the data made available in this article, unless otherwise stated in a credit line to the data. 


\section{Background}

Emergency General Surgery (EGS) patients presenting with urgent need of source control and signs of sepsis remain a clinical challenge. These patients require adequate resuscitation to tolerate the induction of general anesthesia however cannot undergo prolonged resuscitation as they need urgent source control to prevent further deterioration. Despite this being a longstanding problem in surgery, no true optimum amount of pre-operative resuscitation has been defined. There are a variety of recommendations outlining the amount of proper pre-operative resuscitation in this septic patient population however no true guidelines have been established.

The Surviving Sepsis Campaign and the most recent international consensus for sepsis and septic shock (sepsis-3) define sepsis as a life-threatening organ dysfunction caused by a dysregulated host response to infection, with septic shock being a subset of sepsis with circulatory and cellular/metabolic dysfunction $[1,2]$. Fluid resuscitation in sepsis changed in 2001, with the implementation of early goal directed therapy, with sequential fluid boluses to achieve a desired central venous pressure and has subsequently evolved throughout the years [3]. In the latest rendition, the Surviving Sepsis Campaign guidelines recommends a treatment bundle in patients with hypotension, elevated lactate, and signs of sepsis which includes at least $30 \mathrm{~mL} / \mathrm{kg}$ of IV crystalloid, broad spectrum antibiotics and vasopressor use to maintain mean arterial pressure greater than $65[1,4,5]$. Conversely, recent reports have shown increasing mortality high fluid administration and positive fluid balances [6-8]. The World Society of Emergency Surgery recommends prompt diagnosis of sepsis, with adequate resuscitation and total amount of initial resuscitation defined by clinical response without specific fluid goals, except for optimizing tissue perfusion [9]. The optimal amount of pre-operative fluid resuscitation prior to source control is unknown. This study aims to determine if a certain volume of resuscitation prior to surgical source control in septic patients is associated with worsening outcomes.

\section{Methods}

A retrospective review was conducted of a prospectively collected acute care surgery registry at the University of Maryland Medical Center and R Adams Cowley Shock Trauma Center from May 2011 to July 2018.

Patients requiring urgent surgery within $24 \mathrm{~h}$ of admission for surgical source control of intra-abdominal infection were included and only the index admission was included for each patient. These surgeries included, but were not limited to hollow viscous perforation, intraabdominal abscess, and strangulated bowel. Patients undergoing surgery for trauma, hemorrhagic shock, or had their index surgery at an outside hospital were excluded. All patients were resuscitated either prior to transport to our facility, at our University Hospital, or experienced a combination of resuscitation at both locations. The total amount of pre-operative crystalloid fluid resuscitation was recorded. Patients who needed blood transfusions or colloid resuscitation were excluded.

The patients were grouped by increasing volume of resuscitation, in $10 \mathrm{~mL} / \mathrm{kg}$ intervals, up to greater than 70 $\mathrm{mL} / \mathrm{kg}$ prior to operation. The subjects were later dichotomized into less than or greater than or equal to 30 $\mathrm{mL} / \mathrm{kg}$. The electronic medical record (Epic) was reviewed for additional data points. Data collected included presenting vital signs, vasopressor use, height, weight, laboratory values (total bilirubin, creatinine, lactate, platelet count, $\mathrm{PaO} 2$ ) and fractional inspired oxygen requirement. Groups were stratified by quick Sequential Organ Failure Assessment (qSOFA) and standard SOFA scoring systems $[10,11]$.

Mortality was the primary outcome measure for both groupings. Secondary outcomes were measured in the greater or less than $30 \mathrm{~mL} / \mathrm{kg}$ groups, including time to operation or source control, ventilator days, intensive care unit length of stay, and total hospital length of stay.

Bivariate analysis was used to determine mortality per increasing $10 \mathrm{ml} / \mathrm{kg}$ of fluid with Mantel-Haenszel chisquare analysis to determine significance for the trend. Chi-square and Fisher's exact tests were used to compare non-ordinal categorical factors between groups. Continuous data were presented in terms of medians and the interquartile range (IQR; 25th -75 th percentile) and were compared between groups using the Wilcoxon rank-sum test. Multivariable Poisson regression models were fit to determine the association between fluid level and mortality, with and without adjustment by additional covariates. The relationship of each independent variable with mortality was estimated by the relative risk and its $95 \%$ confidence interval.

Permission to conduct this study was obtained from the University of Maryland, Baltimore, Institutional Review Board. As this was a study collected from a previously collected database, the need for written, informed consent was waived by the Institutional Review Board of the University of Maryland. As human subjects were involved, this study protocol was performed in accordance with the relevant guidelines set by the University of Maryland.

\section{Results}

In 7 years, 301 patients met our inclusion criteria for the study (Fig. 1, Table 1). Of the patients included, 152 (50.5\%) were male, had a median age of 55 (IQR 41-69) years and had a BMI of $29.1(24.2-36.9) \mathrm{kg} / \mathrm{m}^{2}$. Median preoperative vital signs included a mean arterial pressure 


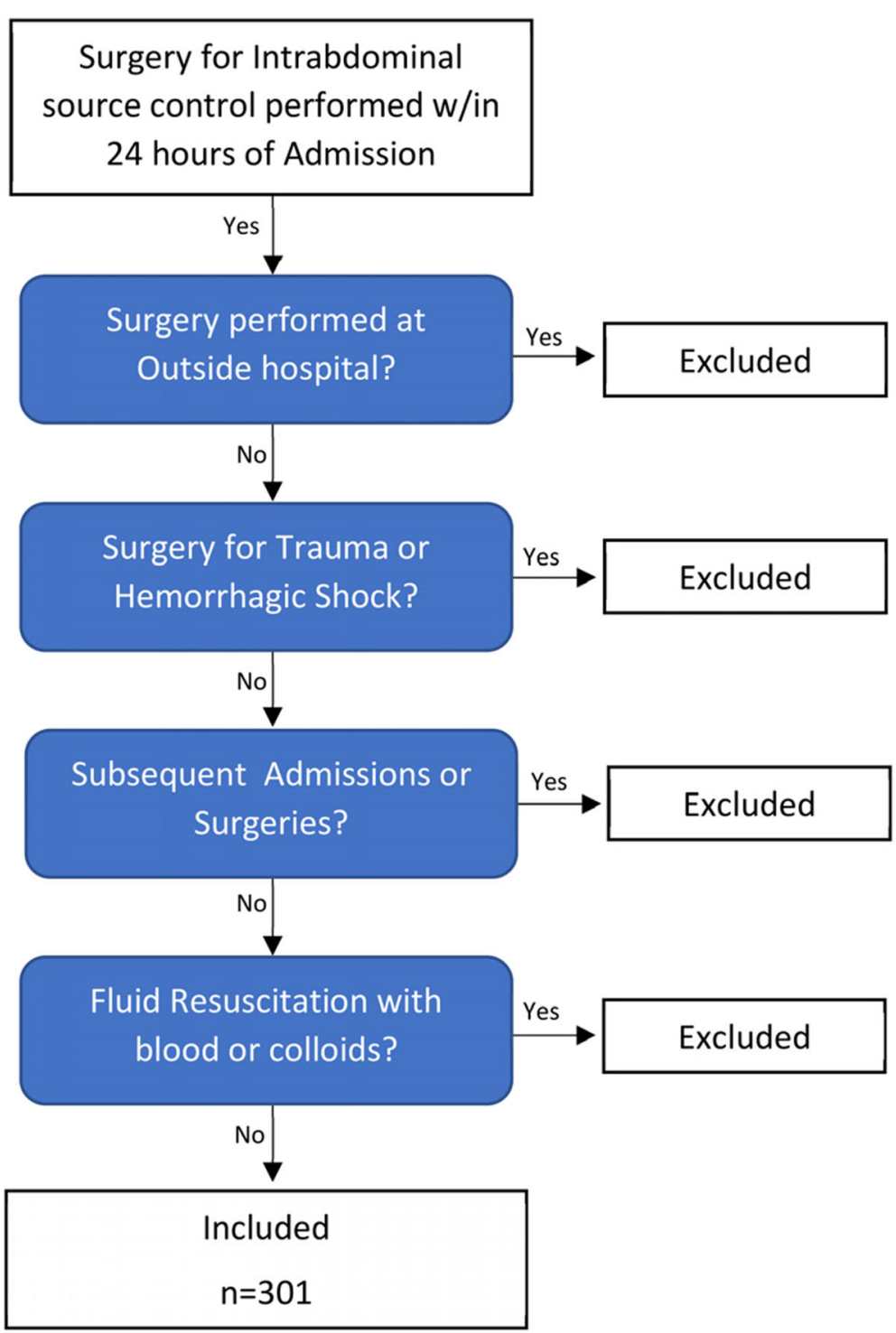

Fig. 1 Study Design, Inclusion/Exclusion

of $86.5 \mathrm{mmHg}$ (74-98.5), systolic blood pressure of 121 $\mathrm{mmHg}$ (106-137), heart rate of 97 beats/min (84-114), respiratory rate of 18 breaths/min (16-23), and a temperature of $98.4^{\circ} \mathrm{F}$ (98.1-99.3). Median preoperative lab values included lactate $1.8 \mathrm{mmol} / \mathrm{L}(1.3-2.9)$, creatinine $1.1 \mathrm{mg} / \mathrm{dL}(0.8-1.8)$, platelet $230 \times 10^{3} / \mathrm{mcL}$ (158311), bilirubin $0.9 \mathrm{mg} / \mathrm{dL}(0.6-1.5)$, and a $\mathrm{PaO} 2130$ mmHg (95-175). These patients presented with median SOFA scores of $2(0-8)$, and qSOFA scores of $1(0-2)$.

The cohort received a median pre-operative fluid resuscitation volume of $19.0 \mathrm{ml} / \mathrm{kg}$ (9.3-35.3), and 85 (28\%) required pre-operative vasopressor use. All required an urgent operation, within $24 \mathrm{~h}$, with a median time to the OR of $5.8 \mathrm{~h}$ (3.3-12.6). Post operatively, these patients experienced average ventilator days of 2 $(0-7)$, intensive care length of stay of $3 \mathrm{~d}(0-12)$, and total hospital length of stay $9 \mathrm{~d}(3-20)$. Overall mortality was $14.6 \%$ (44 patients).

Patients were grouped based upon pre-operative fluid volume in $10 \mathrm{~mL} / \mathrm{kg}$ groups, up to greater or equal than $70 \mathrm{~mL} / \mathrm{kg}$ (Fig. 2). For fluid resuscitation, 80 patients (27\%) received less than $10 \mathrm{~mL} / \mathrm{kg}, 72(24 \%)$ received $10-<20 \mathrm{~mL} / \mathrm{kg}, 51$ (17\%) received $20-<30 \mathrm{~mL} / \mathrm{kg}, 36$ $(12 \%)$ received $30-<40 \mathrm{~mL} / \mathrm{kg}, 20(7 \%)$ received $40-<50$ $\mathrm{mL} / \mathrm{kg}, 10(3 \%)$ received $50-<60 \mathrm{~mL} / \mathrm{kg}, 13(4 \%)$ received $60-<70 \mathrm{~mL} / \mathrm{kg}$, and $19(6 \%)$ received greater than or equal to $70 \mathrm{~mL} / \mathrm{kg}$. Chi-square analysis indicated a significant trend of increasing mortality as fluids per $\mathrm{kg}$ increased, $p=0.004$. Percent mortality and totals in each group is demonstrated by Table 2 .

There was no significant correlation between time to operative source control and mortality ( $p=0.08$, Fig. 3$)$. 
Table 1 Demographics, Vitals, Laboratory Values, Scoring systems, interventions and outcomes

\begin{tabular}{|c|c|c|c|}
\hline Variable & Median & Lower Quartile & Upper Quartile \\
\hline Age (yr) & 55 & 41 & 69 \\
\hline $\mathrm{BMI}\left(\mathrm{kg} / \mathrm{m}^{2}\right)$ & 29.1 & 24.2 & 36.9 \\
\hline HR (beats/min) & 97 & 84 & 114 \\
\hline MAP $(\mathrm{mmHg})$ & 86.5 & 74 & 98.5 \\
\hline $\mathrm{SBP}(\mathrm{mmHg})$ & 121 & 106 & 137 \\
\hline RR (breath/min) & 18 & 16 & 23 \\
\hline Temp $\left({ }^{\circ} \mathrm{F}\right)$ & 98.4 & 98.1 & 99.3 \\
\hline $\mathrm{FiO} 2(\%)$ & 40 & 40 & 50 \\
\hline Bili (mg/dL) & 0.9 & 0.6 & 1.5 \\
\hline Creatinine $(\mathrm{mg} / \mathrm{dL})$ & 1.1 & 0.8 & 1.8 \\
\hline Lactate (mmol/L) & 1.8 & 1.3 & 2.9 \\
\hline Plt $\left(\times 10^{3} / \mathrm{mcL}\right)$ & 230 & 158 & 311 \\
\hline $\mathrm{PaO} 2$ (mkmHg) & 130 & 95 & 175 \\
\hline SOFA & 2 & 0 & 8 \\
\hline qSOFA & 1 & 0 & 2 \\
\hline Time to OR (hour) & 5.8 & 3.3 & 12.6 \\
\hline Fluids/Kg (mL/Kg) & 19.0 & 9.3 & 35.3 \\
\hline Ventilator Days & 2 & 0 & 7 \\
\hline ICU LOS (day) & 3 & 0 & 12 \\
\hline LOS (day) & 9 & 3 & 20 \\
\hline
\end{tabular}

$B M I$ body mass index, MAP mean arterial pressure, $S B P$ systolic blood pressure, $\mathrm{FiO} 2$ fractional inspired oxygen, $\mathrm{PaO} 2$ partial pressure of oxygen, SOFA sequential organ failure assessment score, qSOFA quick sequential organ failure assessment score

Patients were additionally grouped into less than and greater than or equal to $30 \mathrm{~mL} / \mathrm{kg}$ of fluid resuscitation. There were 203 patients $(67 \%)$ who received less than $30 \mathrm{~mL} / \mathrm{kg}$ of fluid, and 98 patients (33\%) who received greater than or equal to $30 \mathrm{~mL} / \mathrm{kg}$ (Table 3). These patient groups were similar in age and gender. Each group had similar presenting heart rates, medians 96 and $101(p=0.21)$, however, had significant differences in mean arterial pressure, $88 \mathrm{mmHg}$ vs $82 \mathrm{mmHg}(p<$ $0.001), \mathrm{SBP}, 124 \mathrm{mmHg}$ vs $113 \mathrm{mmHg}(p=0.001)$ and initial lactate, 1.8 vs $2.3(p=0.002)$. These groups scored similar on qSOFA, 1 vs $1(p=0.06)$. The patients in the $<30 \mathrm{~mL} / \mathrm{kg}$ group received significantly less fluid, with median fluid/kg 12.9 vs 46.9 ( $p<0.001)$. Despite more resuscitation, patients $\geq 30 \mathrm{~mL} / \mathrm{kg}$ more frequently required vasopressors $37 \%$ vs $24 \%$ ( $p=0.02$ ).

Mortality was significantly lower in patients who received less fluid, $11 \%$ vs $21 \%(p=0.02)$. Median Ventilatory days ( 1 vs 3 ), ICU LOS (2 vs 4 ) and hospital LOS (8 vs 9) were all lower with fewer fluids, however the differences were not statistically significant.

Further analyses compared patients who survived versus non-survivors (Table 4). Survivors had a significantly lower average age 53 vs $65(p<0.001)$ and presented with lower SOFA 2.0 vs $10.5,(p<0.001)$ and qSOFA (1.0 vs $2.0, p<0.001)$ scores. Survivors presented with better vital signs, including higher MAP $(90 \mathrm{mmHg}$ vs $72 \mathrm{mmHg}, p<0.001$ ), lower heart rates (96 bpm vs 105 bpm, $p=0.02)$ and a lower respiratory rate (18 vs 22 breaths per minute, $p=0.005)$. Survivors had better baseline physiology and renal function with a lower lactate $(1.7 \mathrm{vs} 3.2 \mathrm{mmol} / \mathrm{L}, p<0.001)$ and creatinine (1.0 vs $2.0 \mathrm{mg} / \mathrm{dl}, p<0.001)$. Patients who survived required on average lower volumes of fluid per kilogram (17.8 vs $27.4 \mathrm{~mL} / \mathrm{kg}, p=0.007$ ) and only $21 \%$ of survivors compared with $68 \%$ of non-survivors required pre-operative vasopressors $(p<0.001)$. Lastly, non-survivors tended to have operative source control quicker than survivors (4.1 h vs $6.2 \mathrm{~h}, p=0.06$ ).

A regression model measuring the unadjusted effect of binary fluid level on mortality on the cohort of 301



Fig. 2 Percent Mortality with increasing $10 \mathrm{ml} / \mathrm{kg}$ fluid resuscitation 
Table 2 Percent Mortality with increasing $10 \mathrm{ml} / \mathrm{kg}$ fluid resuscitation

\begin{tabular}{|c|c|c|c|}
\hline \multicolumn{4}{|l|}{ Fluids per Kg by Mortality } \\
\hline Fluid per $\mathrm{Kg}$ & Survived & Died & Total \\
\hline$<10 \mathrm{~mL} / \mathrm{kg}$ & $73(91.3 \%)$ & 7 (8.8\%) & 80 \\
\hline $10-<20 \mathrm{~mL} / \mathrm{kg}$ & $62(86.1 \%)$ & $10(13.9 \%)$ & 72 \\
\hline $20-<30 \mathrm{~mL} / \mathrm{kg}$ & $45(88.2 \%)$ & $6(11.8 \%)$ & 51 \\
\hline $30-<40 \mathrm{~mL} / \mathrm{kg}$ & $29(80.6 \%)$ & $7(19.4 \%)$ & 36 \\
\hline $40-<50 \mathrm{~mL} / \mathrm{kg}$ & $18(90.0 \%)$ & $2(10.0 \%)$ & 20 \\
\hline $50-<60 \mathrm{~mL} / \mathrm{kg}$ & $9(90.0 \%)$ & $1(10.0 \%)$ & 10 \\
\hline $60-<70 \mathrm{~mL} / \mathrm{kg}$ & $8(61.5 \%)$ & $5(38.5 \%)$ & 13 \\
\hline $70+\mathrm{mL} / \mathrm{kg}$ & $13(68.4 \%)$ & $6(31.6 \%)$ & 19 \\
\hline Total & 257 & 44 & 301 \\
\hline Statistic & DF & Value & Prob \\
\hline Mantel-Haenszel Chi-Square & 1 & 8.4864 & 0.0036 \\
\hline
\end{tabular}

patients (Table 5) indicated that patients treated with 30 or more $\mathrm{mL} / \mathrm{kg}$ were 1.89 times as likely to die than those treated with fluids below $30 \mathrm{~mL} / \mathrm{kg}$ (95\% CI 1.103.25, $p=0.02$ ). Upon adjustment by covariates (age, MAP, SBP, heart rate, lactate, creatinine and SOFA score), the amount of fluid administered was no longer statistically significant $(p=0.59)$. Significant risk factors for mortality in the adjusted model included increasing age $(p=0.001)$, increasing lactate $(p<0.001)$, and increasing SOFA $(p<0.001)$ levels. The inclusion of lactate in the latter model reduced the patient sample size in the model to 247 . In a separate model without lactate $(N=299)$, increasing age and SOFA remained as the only statistically significant risk factors for death.

Similar results were found when analyzing the effect of increasing volume by $10 \mathrm{ml} / \mathrm{kg}$ intervals on mortality (Table 6). An unadjusted model indicated that mortality risk significantly increased by $14 \%$ for every $10 \mathrm{~mL} / \mathrm{kg}$ increase in fluid volume $(\mathrm{RR}=1.14,95 \% \mathrm{CI} 1.07-1.21$, $p<0.001$ ). Fluid volume was no longer significant ( $p=$ 0.78 ) when adjusted by the covariates listed above, replaced by increasing age $(p=0.002)$, lactate $(p<0.001)$ and SOFA $(p<0.001)$ levels as significant risk factors in a model with lactate and by increasing age and SOFA in a separate model without lactate.

\section{Discussion}

This study represents one of the first studies examining the amount of pre-operative fluid resuscitation in patients who need urgent source control of intraabdominal infection. We sought to answer the age-old question, of how much resuscitation is needed prior to surgery. Our initial data analysis demonstrates that increasing fluid resuscitation prior to source control was independently associated with a significant increase in mortality (Fig. 2). This study aligns with other reports showing an increase in mortality with increasing fluids $[6-8,12,13]$ and others advocating for trials of decreasing fluid resuscitation [14, 15]. This data differed when adjusting for covariates. In the unadjusted model, patients who received greater than $30 \mathrm{ml} / \mathrm{kg}$ of volume had and increased mortality by 1.89 times, however when adjusting for covariates (age, MAP, SBP, heart rate, lactate, creatinine and SOFA score, Table 5) increasing fluid resuscitation was no longer associated with mortality in our multivariate model. This change in significance is likely the result of sicker and more physiologically deranged patients receiving and requiring more fluids for adequate pre-operative resuscitation.

With the thought that 'sicker' patients require more fluid resuscitation, we sought to compare how 'sick' each group was. In addition to the multivariate model, we separated our sample size into two groups, based on the Surviving Sepsis Campaign resuscitation guidelines of

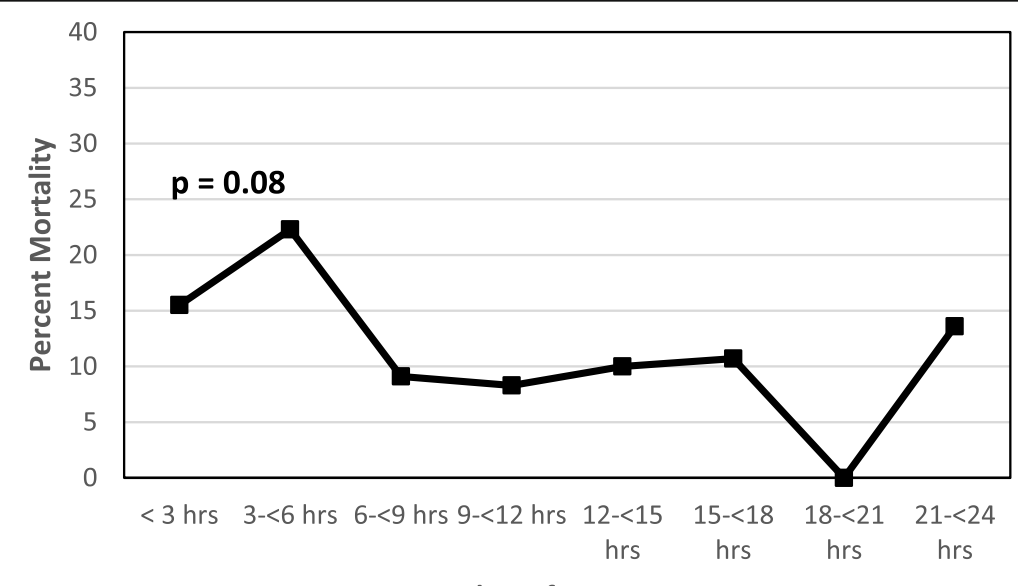

Number of Hours to OR

Fig. 3 Mortality with Time to Operative Source Control 
Table $3<30 \mathrm{~mL} / \mathrm{kg}$ vs $\geq 30 \mathrm{~mL} / \mathrm{kg}$. Reported as standard deviations unless otherwise stated

\begin{tabular}{|c|c|c|c|}
\hline & $\begin{array}{l}<30 \mathrm{ml} / \mathrm{kg}(n=203) \\
\text { Median (IQR) }\end{array}$ & $\begin{array}{l}\geq 30 \mathrm{ml} / \mathrm{kg}(n=98) \\
\text { Median (IQR) }\end{array}$ & $\begin{array}{l}p- \\
\text { value }\end{array}$ \\
\hline Age & $55(41-68)$ & $56(44-71)$ & 0.46 \\
\hline Male, n (\%) & $106(52 \%)$ & $46(47 \%)$ & 0.39 \\
\hline HR & $96(82-112)$ & $101(85-118)$ & 0.21 \\
\hline MAP & $88(75-102)$ & $82(70-93)$ & $<0.001$ \\
\hline SBP & $124(109-140)$ & $113(102-129)$ & 0.001 \\
\hline Lactate $(n=166 / 81)$ & $1.8(1.2-2.6)$ & $2.3(1.5-4.4)$ & 0.002 \\
\hline Total Fluids & $12.9(4.7-20.0)$ & $46.9(37.8-64.7)$ & $<0.001$ \\
\hline Preoperative Vasopressor & $49(24 \%)$ & $36(37 \%)$ & 0.02 \\
\hline Time to OR (Hours) & $6.1(3.5-12.2)$ & $4.9(2.7-13.1)$ & 0.11 \\
\hline Sofa & $2(0-7)$ & $3(1-10)$ & 0.05 \\
\hline qSOFA & $1(0-1)$ & $1(0-2)$ & 0.06 \\
\hline $\operatorname{LOS}(d)$ & $8(3-19)$ & $9(3-23)$ & 0.57 \\
\hline ICU LOS (d) & $2(0-11)$ & $4(0-13)$ & 0.22 \\
\hline Ventilator Days & $1(0-6)$ & $3(0-7)$ & 0.08 \\
\hline Mortality & $23(11 \%)$ & $21(21 \%)$ & 0.02 \\
\hline
\end{tabular}

Table 4 Comparison of variables of survivors vs non-survivors, expressed as medians and interquartile range, except otherwise noted

\begin{tabular}{|c|c|c|c|}
\hline \multicolumn{4}{|c|}{ Survivors vs Non-Survivors } \\
\hline & Survived $(n=257)$ & Died $(n=44)$ & $p$-value \\
\hline \multicolumn{4}{|l|}{ Demographics } \\
\hline Age (years) & $53(38-67)$ & $65(58-72)$ & $<0.001$ \\
\hline \multicolumn{4}{|l|}{ Vitals } \\
\hline HR (beats/minute) & $96(83-112)$ & $105(93-122)$ & 0.02 \\
\hline MAP (mmHg) & $90(76-101)$ & $72(66-79)$ & $<0.001$ \\
\hline $\mathrm{SBP}(\mathrm{mmHg})$ & $123(109-139)$ & $106(91-116)$ & $<0.001$ \\
\hline RR (breaths/minute) & $18(16-22)$ & $22(18-29)$ & 0.005 \\
\hline Temp ( $\left.{ }^{\circ} \mathrm{F}\right)$ & $98.4(98.1-99.3)$ & $98.1(96.6-99.9)$ & 0.24 \\
\hline \multicolumn{4}{|l|}{ Laboratory Values } \\
\hline Bilirubin (mg/dL) & $0.9(0.6-1.4)$ & $1.5(1.1-2.5)$ & $<0.001$ \\
\hline Creatinine (mg/dL) & $1.0(0.8-1.4)$ & $2.0(1.4-3.2)$ & $<0.001$ \\
\hline Lactate(mmol/L) & $1.7(1.2-2.6)$ & $3.2(1.8-6.9)$ & $<0.001$ \\
\hline Platelet $\left(\times 10^{3} / \mathrm{mcL}\right)$ & $240(175-314)$ & $167(97-283)$ & 0.001 \\
\hline \multicolumn{4}{|l|}{ Scoring Systems } \\
\hline SOFA & $2.0(0-6)$ & $10.5(6-14)$ & $<0.001$ \\
\hline qSOFA & $1.0(0-1)$ & $2.0(1-3)$ & $<0.001$ \\
\hline \multicolumn{4}{|l|}{ Interventions } \\
\hline Pre-op Vasopressor & $55(21 \%)$ & $30(68 \%)$ & $<0.001$ \\
\hline Time to OR (hours) & $6.2(3.3-13.0)$ & $4.1(3.3-7.6)$ & 0.06 \\
\hline Fluids per $\mathrm{Kg}(\mathrm{mL} / \mathrm{kg})$ & $17.8(8.6-32.7)$ & $27.4(14.3-59.6)$ & 0.007 \\
\hline
\end{tabular}

those who received $<30 \mathrm{~mL} / \mathrm{Kg}$ or $\geq 30 \mathrm{~mL} / \mathrm{kg}$. Both groups had similar demographics with respect to male/ female ( $52 \%$ vs $47 \%$ ) and similar age (55 vs 56 ). These groups were similar in qSOFA scores, however the presenting physiology differed. The patients who received more fluids had significantly greater severity of illness on admission, with lower MAP (82 vs 88), lower SBP (113 vs 124$)$, and higher lactate (2.3 vs 1.8 ). Patients with worse physiology received more preoperative fluid resuscitation and required more vasopressors prior to the

Table 5 Relative risk regression model for mortality for those treated with $<30$ or $\geq 30 \mathrm{ml} / \mathrm{kg}$, and adjusted for covariate risk factors

Relative Risks for Risk Factors of Mortality Effect of Fluid Volume $30+\mathrm{ml} / \mathrm{kg}$ vs. $<30 \mathrm{ml} / \mathrm{kg}$

\begin{tabular}{lllll}
\hline & \multicolumn{5}{c}{$\mathbf{9 5 \%} \mathbf{C l}$ for RR } \\
Unadjusted Model $(\mathbf{N = 3 0 1 )}$ & $\mathbf{R R}$ & Lower & Upper & $\boldsymbol{p}$-value \\
$30+\mathrm{ml} / \mathrm{kg}$ vs. $<30 \mathrm{ml} / \mathrm{kg}$ & 1.89 & 1.10 & 3.25 & 0.02 \\
& \multicolumn{5}{c}{$\mathbf{9 5 \%} \mathbf{C l}$ for RR } \\
Adjusted Model $(\mathbf{N}=\mathbf{2 4 7})$ & $\mathbf{R R}$ & Lower & Upper & $\boldsymbol{p}$-value \\
$30+\mathrm{ml} / \mathrm{kg}$ vs. $<30 \mathrm{ml} / \mathrm{kg}$ & 1.15 & 0.69 & 1.92 & 0.59 \\
Age (years) & 1.03 & 1.01 & 1.05 & 0.001 \\
MAP $(\mathrm{mmHg})$ & 0.99 & 0.97 & 1.02 & 0.63 \\
SBP $(\mathrm{mmHg})$ & 1.00 & 0.98 & 1.02 & 0.77 \\
Heart rate $($ beats/minute) & 1.01 & 1.00 & 1.02 & 0.20 \\
Lactate $(\mathrm{mmol} / \mathrm{L})$ & 1.09 & 1.05 & 1.14 & $<0.001$ \\
Creatinine $(\mathrm{mg} / \mathrm{dL}$ & 1.00 & 0.86 & 1.17 & 0.95 \\
SOFA & 1.13 & 1.07 & 1.19 & $<0.001$ \\
\hline
\end{tabular}


Table 6 Relative risk regression model for mortality for those treated with increasing amounts of fluid by $10 \mathrm{~mL} / \mathrm{kg}$ and adjusted for covariate risk factors

\begin{tabular}{|c|c|c|c|c|}
\hline \multicolumn{5}{|c|}{$\begin{array}{l}\text { Relative Risks for Risk Factors of Mortality Effect of Fluid Volume } \\
\text { in Increasing } 10 \mathrm{ml} / \mathrm{kg} \text { Intervals }\end{array}$} \\
\hline \multirow[b]{2}{*}{ Unadjusted Model $(N=301)$} & \multirow[b]{2}{*}{$\mathrm{RR}$} & \multicolumn{2}{|c|}{$95 \% \mathrm{Cl}$ for $\mathrm{RR}$} & \multirow[b]{2}{*}{$p$-value } \\
\hline & & Lower & Upper & \\
\hline \multirow[t]{2}{*}{$10 \mathrm{ml} / \mathrm{kg}$ Increase in Fluid Volume } & 1.14 & 1.07 & 1.21 & $<0.001$ \\
\hline & & \multicolumn{2}{|c|}{$95 \% \mathrm{Cl}$ for $\mathrm{RR}$} & \\
\hline Adjusted Model $(N=247)$ & $\mathbf{R R}$ & Lower & Upper & $p$-value \\
\hline $10 \mathrm{ml} / \mathrm{kg}$ Increase in Fluid Volume & 1.01 & 0.93 & 1.10 & 0.78 \\
\hline Age (years) & 1.03 & 1.01 & 1.05 & 0.002 \\
\hline MAP $(\mathrm{mmHg})$ & 0.99 & 0.97 & 1.02 & 0.65 \\
\hline $\mathrm{SBP}(\mathrm{mmHg})$ & 1.00 & 0.98 & 1.02 & 0.74 \\
\hline Heart rate (beats/minute) & 1.01 & 1.00 & 1.02 & 0.20 \\
\hline Lactate (mmol/L) & 1.10 & 1.05 & 1.15 & $<0.001$ \\
\hline Creatinine $(\mathrm{mg} / \mathrm{dL}$ & 1.02 & 0.88 & 1.17 & 0.83 \\
\hline SOFA & 1.12 & 1.07 & 1.19 & $<0.001$ \\
\hline
\end{tabular}

operating room. Interestingly, more fluids did not translate into delay to operative source control, as these patients had similar times to operation ( 4.9 vs $6.1 \mathrm{~h}$ ). When examining outcomes, patients who received more fluids tended to have increased ventilator days, ICU and hospital lengths of stay, though none of these comparisons were statistically significant. Patients who received more fluids had nearly double the mortality rate, $21 \%$ vs $11 \%(p=0.02)$.

Comparing survivors vs non-survivors, non-survivors were older and had greater severity of illness demonstrated by worse presenting physiology. Non-survivors were more tachycardic (105 vs 96 beats/min), tachypneic (22 vs 18 breaths/min), and hypotensive (SPB 106 vs $123 \mathrm{mmHg}$ ) compared to survivors. Physiology was deranged as well, with non-survivors on average having higher lactate, 3.2 vs 1.7, and baseline organ dysfunction, Cr 2.0 vs $1.0 \mathrm{mg} / \mathrm{dl}$, bilirubin $1.5 \mathrm{vs} 0.9 \mathrm{mg} / \mathrm{dl}$. Severity of illness scores were worse in non-survivors, with presenting SOFA scores of 10.5 vs 2.0, and qSOFA scores of 2.0 vs 1.0. These findings align with the current knowledge that physiologically deranged patients, aka 'sicker', do worse $[2,9,10,16,17]$. Additionally, sicker patients often require more fluids, as was the case in our series.

The relative risk regression model, without adjusting for lactate we demonstrated significant increases in mortality with greater fluid administration (Tables 5 and 6). However, when the model was adjusted for lactate, the only significant increases in mortality were increasing age, increasing lactate, and higher presenting SOFA scores (Tables 5 and 6). Volume of resuscitation did not have a significant impact on mortality. This differs some recent reports showing high fluid administration and positive fluid balances increasing mortality [6-8]. With respect to factors associated with worsening outcomes, out study aligns with current reports and scoring systems that show increasing age, worse physiology and organ failure scores are associated with increased mortality $[2,9,10,16,17]$.

There were several limitations of this study. First of the 301 patients that met inclusion criteria, all patients were resuscitated either prior to transport to our facility, at our University Hospital, or by a combination of resuscitation at both locations. One limitation of our study, due to the retrospective nature of our study, was that there were no controls on the types of crystalloid fluid (normal saline, lactated ringers, or Plasma-Lyte) administration used for resuscitation. Additionally, patients had varying places of resuscitation, requiring resuscitation in outside emergency departments, outside hospitals, our university emergency room, or our university critical care resuscitation unit which may have impacted the total amount of fluid administration. Differences in outcome per type of fluid administered with relation to balanced vs normal saline were not recorded and may have impacted results as seen in the Balanced Crystalloids versus Saline in Critically Ill and Noncritically Ill adults (SMART) and Saline against Lactated Ringer's or Plasma-Lyte in the Emergency Department (SALT-ED) trials [18-20].

Additionally, the timing of administration, type of vasopressor used, and total amount of vasopressors were not captured with our database. Thus vasopressor use was not uniform throughout the study time period and varied by each treating physician which may have an impact on results $[1,21]$. Thirdly, there was no uniform protocol for operative intervention in these patients, and need for operative source control was determined by the attending surgeon which may have impacted times to operative intervention. Lastly, we did not collect time to antibiotic administration or presence of antibiotic administration, which may have contributed mortality in these septic patients $[1,16]$.

The final limitation in our study relates to how 'sick' our patients were. Sepsis 3 defines sepsis as qSOFA $>2$ with septic shock as qSOFA $>2$, Lactate $>2$ and/or vasopressor use [5]. A large proportion of our patients did not meet these criteria for sepsis or septic shock and thus may have done with will any volume of preoperative fluid resuscitation. Future studies will be needed to look specifically at the population of patients who are septic or are in septic shock.

\section{Conclusion}

In our cohort of patients, using an adjusted regression model, we did not find a significant association between the amount of pre-operative fluid resuscitation and 
mortality but observed significant increases in mortality with increased age, lactate levels, and SOFA scores. The amount of pre-operative volume resuscitation was not associated with differences in time to operative source control, ventilator days, ICU or total hospital LOS. Patients who died had deranged physiology and evidence of organ dysfunction on admission. In our series the amount of preoperative fluid resuscitation was not associated with mortality, showing that the total amount of preoperative fluid resuscitation does not impact mortality. This one of the first studies of its kind examining pre-operative fluid resuscitation, but further studies are needed to answer the question of what is the optimal amount of preoperative fluid resuscitation in the septic emergency surgery patient.

\section{Abbreviations}

EGS: Emergency General Surgery (EGS); ICU: Intensive Care Unit; SOFA: Sequential Organ Failure Assessment Score; qSOFA: Quick Sequential Organ Failure Assessment Score; IQR: Interquartile range; BMI: Body mass index; MAP: Mean arterial pressure; SBP: Systolic blood pressure; FiO2: Fractional inspired oxygen; $\mathrm{PaO} 2$ : Partial pressure of oxygen; LOS: Length of stay

\section{Acknowledgements}

N/A

\section{Authors' contributions}

BM collected, analyzed and interpreted the data, and was a major contributor to the manuscript. BM wrote the manuscript. EM assisted in data collection. JK performed the statistical analysis of the data and contributed to the manuscript. ST and JD contributed with the editing and evaluation of the manuscript. The author(s) read and approved the final manuscript.

\section{Authors' information}

BM holds board certifications in General Surgery and Surgical Critical Care from the American College of Surgeons. BM is a Acute Care, Trauma, and Surgical Critical Care Attending at Einstein Medical Center in Philadelphia, USA

\section{Funding}

There are no sources of funding for this project.

\section{Availability of data and materials}

The datasets analyzed during the current study are not available publicly, as they are part of a prospectively collected database. The de-identified dataset is available on request from the corresponding author.

\section{Declarations}

Ethics approval and consent to participate

This study was approved by the University of Maryland Internal Review board.

This was a study was a retrospective review of a previously collected database, the need for written, informed consent was waived by the Institutional Review Board of the University of Maryland.

\section{Consent for publication}

No individual personal data used. N/A.

\section{Competing interests}

The authors declare that they have no competing interests.

\section{Author details}

${ }^{1}$ Einstein Healthcare Network, Sidney Kimmel Medical College at Thomas Jefferson University, Einstein Medical Center, Klein Building, Suite 101, 5401
Old York Road, Philadelphia, PA 19141, USA. ${ }^{2}$ R Adams Cowley Shock Trauma Center, University of Maryland School of Medicine, Baltimore, MD, USA.

Received: 26 January 2021 Accepted: 23 June 2021

Published online: 22 July 2021

\section{References}

1. Rhodes A, Evans LE, Alhazzani W, Levy MM, Antonelli M, Ferrer R, et al. Surviving Sepsis campaign: international guidelines for Management of Sepsis and Septic Shock: 2016. Intensive Care Med. 2017;43(3):304-77. https://doi.org/10.1007/s00134-017-4683-6.

2. Singer M, Deutschman CS, Seymour CW, Shankar-Hari M, Annane D, Bauer $M$, et al. The third international consensus definitions for Sepsis and septic shock (Sepsis-3). JAMA. 2016;315(8):801-10. https://doi.org/10.1001/jama.201 6.0287

3. Rivers E, Nguyen B, Havstad S, Ressler J, Muzzin A, Knoblich B, et al. Early goal-directed therapy in the treatment of severe Sepsis and septic shock. N Engl J Med. 2001;345(19):1368-77. https://doi.org/10.1056/NEJMoa010307.

4. Levy MM, Evans LE, Rhodes A. The surviving Sepsis campaign bundle: 2018 update. Intensive Care Med. 2018:44(6):925-8. https://doi.org/10.1007/ s00134-018-5085-0.

5. Rhodes A, Evans LE, Alhazzani W, Levy MM, Antonelli M, Ferrer R, et al. Surviving Sepsis campaign: international guidelines for Management of Sepsis and Septic Shock: 2016. Crit Care Med. 2017;45(3):486-552. https:// doi.org/10.1097/CCM.0000000000002255.

6. Acheampong A, Vincent J-L. A positive fluid balance is an independent prognostic factor in patients with sepsis. Crit Care. 2015;19(1). Available from: https://www.ncbi.nlm.nih.gov/pmc/articles/PMC4479078/ [cited 28 Jan 2020]

7. Boyd JH, Forbes J, Nakada T, Walley KR, Russell JA. Fluid resuscitation in septic shock: a positive fluid balance and elevated central venous pressure are associated with increased mortality. Crit Care Med. 2011;39(2):259-65. https://doi.org/10.1097/CCM.0b013e3181feeb15.

8. de Oliveira FSV, Freitas FGR, Ferreira EM, de Castro I, Bafi AT, de Azevedo $L C P$, et al. Positive fluid balance as a prognostic factor for mortality and acute kidney injury in severe sepsis and septic shock. J Crit Care. 2015;30(1): 97-101. https://doi.org/10.1016/j.jcrc.2014.09.002.

9. Sartelli M, Chichom-Mefire A, Labricciosa FM, Hardcastle T, Abu-Zidan FM, Adesunkanmi AK, et al. The management of intra-abdominal infections from a global perspective: 2017 WSES guidelines for management of intraabdominal infections. World J Emerg Surg WJES. 2017;12(1):29. https://doi. org/10.1186/s13017-017-0141-6.

10. Vincent JL, Moreno R, Takala J, Willatts S, De Mendonça A, Bruining H, et al. The SOFA (Sepsis-related organ failure assessment) score to describe organ dysfunction/failure. On behalf of the working group on Sepsis-related problems of the European Society of Intensive Care Medicine. Intensive Care Med. 1996;22(7):707-10. https://doi.org/10.1007/BF01709751.

11. Seymour CW, Liu VX, Iwashyna TJ, Brunkhorst FM, Rea TD, Scherag A, et al. Assessment of clinical criteria for Sepsis: for the third international consensus definitions for Sepsis and septic shock (Sepsis-3). JAMA. 2016; 315(8):762-74. https://doi.org/10.1001/jama.2016.0288.

12. Volume Overload: Prevalence, Risk Factors, and Functional Outcome in Survivors of Septic Shock. - PubMed - NCBI. Available from: https://www. ncbi.nlm.nih.gov/pubmed/26394090 . [cited 21 Mar 2020].

13. Brotfain E, Koyfman L, Toledano R, Borer A, Fucs L, Galante O, et al. Positive fluid balance as a major predictor of clinical outcome of patients with sepsis/septic shock after ICU discharge. Am J Emerg Med. 2016;34(11):21226. https://doi.org/10.1016/j.ajem.2016.07.058.

14. Silversides JA, Fitzgerald E, Manickavasagam US, Lapinsky SE, Nisenbaum R, Hemmings $N$, et al. Deresuscitation of patients with iatrogenic fluid overload is associated with reduced mortality in critical illness. Crit Care Med. 2018;46(10):1600-7. https://doi.org/10.1097/CCM.0000000000003276.

15. Macdonald SPJ, Keijzers G, Taylor DM, Kinnear F, Arendts G, Fatovich DM, et al. Restricted fluid resuscitation in suspected sepsis associated hypotension (REFRESH): a pilot randomised controlled trial. Intensive Care Med. 2018;44(12):2070-8. https://doi.org/10.1007/s00134-018-5433-0.

16. Dellinger RP, Levy MM, Rhodes A, Annane D, Gerlach H, Opal SM, et al. Surviving sepsis campaign: international guidelines for management of severe sepsis and septic shock: 2012 Crit Care Med. 2013:41(2):580-637. https://doi.org/10.1097/CCM.0b013e31827e83af. 
17. Bauer M, Gerlach H, Vogelmann T, Preissing F, Stiefel J, Adam D. Mortality in sepsis and septic shock in Europe, North America and Australia between 2009 and 2019- results from a systematic review and meta-analysis. Crit Care. 2020;24(1):239. https://doi.org/10.1186/s13054-020-02950-2.

18. Semler MW, Self WH, Wanderer JP, Ehrenfeld JM, Wang L, Byrne DW, et al. Balanced crystalloids versus saline in critically ill adults. N Engl J Med. 2018; 378(9):829-39. https://doi.org/10.1056/NEJMoa1711584.

19. Self WH, Semler MW, Wanderer JP, Wang L, Byrne DW, Collins SP, et al. Balanced crystalloids versus saline in noncritically ill adults. N Engl J Med. 2018;378(9):819-28. https://doi.org/10.1056/NEJMoa1711586.

20. Brown RM, Wang L, Coston TD, Krishnan NI, Casey JD, Wanderer JP, et al. Balanced crystalloids versus saline in Sepsis. A secondary analysis of the SMART clinical trial. Am J Respir Crit Care Med. 2019;200(12):1487-95. https://doi.org/10.1164/rccm.201903-05570C.

21. Beck V, Chateau D, Bryson GL, Pisipati A, Zanotti S, Parrillo JE, et al. Timing of vasopressor initiation and mortality in septic shock: a cohort study. Crit Care. 2014;18(3):R97. https://doi.org/10.1186/cc13868.

\section{Publisher's Note}

Springer Nature remains neutral with regard to jurisdictional claims in published maps and institutional affiliations.

Ready to submit your research? Choose BMC and benefit from:

- fast, convenient online submission

- thorough peer review by experienced researchers in your field

- rapid publication on acceptance

- support for research data, including large and complex data types

- gold Open Access which fosters wider collaboration and increased citations

- maximum visibility for your research: over $100 \mathrm{M}$ website views per year

At $\mathrm{BMC}$, research is always in progress.

Learn more biomedcentral.com/submissions 